DOI 10.37882/2223-2982.2021.12.14

\title{
ИННОВАЦИОННЫЙ ПОДХОД К ФОРМИРОВАНИЮ ГОТОВНОСТИ БАКАЛАВРОВ ТОВАРОВЕДЕНИЯ К ПРОФЕССИОНАЛЬНОЙ ЭКСПЕРТНОЙ ДЕЯТЕЛЬНОСТИ
}

\section{AN INNOVATIVE APPROACH TO THE FORMATION OF THE READINESS OF BACHELORS OF COMMODITY SCIENCE FOR PROFESSIONAL EXPERT ACTIVITY}

\section{Krotova}

G. Rybakova

E. Fedchenko

Summary: The article deals with the actual problems of higher commodity science education, to which the authors attribute the violation of meaningful continuity between the levels of professional education; the lack of commodity science of non-food and part of food products in the list of scientific specialties; the uncertainty of the status of the science "commodity science"; insufficient development of theoretical and methodological tools used to solve the problems of commodity science education.

The authors place a special emphasis in the article on the problem of forming the readiness of future bachelors of commodity science for professional expert activity. As one of the possible solutions to this problem, the implementation of the author's professional training program "Path to the specialty" is proposed, the methodological basis of which is a combination of systemic, activity-based and reflexive approaches. The core of this program was the involvement of future bachelors of commodity science in the process of preparing and implementing the procedure for consumer testing of goods, followed by analysis of the data obtained and reflection on their own achievements. The experience of implementing this program in the educational practice of the Siberian Federal University has confirmed its effectiveness and efficiency.

Keywords: commodity science, professional activity, bachelor of commodity science, readiness, innovative methods.

\author{
Кротова Ирина Владимировна \\ Д.п.н., дочент, Сибирский федеральный университет \\ (2. Красноярск) \\ IKrotova@sfu-kras.ru \\ Рыбакова Галина Раисовна \\ К.б.н., доцент, Сибирский федеральный университет \\ (2. Красноярск) \\ GRybakova@sfu-kras.ru \\ Федченко Елена Александровна \\ старший преподаватель, Сибирский федеральный \\ университет (2. Красноярск) \\ EFedchenko@sfu-kras.ru
}

Аннотация: В статье рассмотрены актуальные проблемы высшего товароведного образования, к которым авторы относят нарушение содержательной преемственности между уровнями профессионального образования; отсутствие товароведения непродовольственных и части продовольственных товаров в перечне научных специальностей; неопределенность статуса самой науки «товароведение»; недостаточная разработанность теоретикометодического инструментария, используемого для решения проблем товароведного образования.

Особый акцент в статье авторы делают на проблеме формирования готовности будущих бакалавров товароведения к профессиональной экспертной деятельности. В качестве одного из возможных вариантов решения данной проблемы предлагается реализация авторской программы профессиональной подготовки «Путь в специальность», методологическим базисом которой выступила совокупность системного, деятельностного и рефлексивного подходов. Ядром данной программы явилось вовлечение будущих бакалавров товароведения в процесс подготовки и реализации процедуры потребительского тестирования товаров с последующим анализом полученных данных и рефлексией собственных достижений. Опыт внедрения указанной программы в образовательную практику Сибирского федерального университета подтвердил её эффективность и результативность.

Ключевые слова: товароведение; профессиональная деятельность; бакалавр товароведения; готовность; инновационные методы.

личности вызвали значительные изменения в содержании высшего образования. Как следствие, переработан ряд поколений ФГОС ВО, которые в компетентностном контексте интегрируют запросы всех заинтересованных субъектов к содержательной стороне подготовки выпускника высшей школы; реализована вариативность содержания, формируемая на усмотрение вуза; созданы условия для активного включения в образовательную деятельность специалистов-практиков и многое другое. Однако, несмотря на российские образовательные инновации, проблема формирования готовности выпускника вуза к профессиональной деятельности по- 
прежнему остается актуальной, что свидетельствует о высоком уровне сложности и недостаточной эффективности используемого теоретико-методического инструментария для её решения.

\section{^итературный обзор}

Вопросы товароведного образования рассмотрены в трудах Бакайтис В.И., Васильевой Н.О., Кротовой И.В., Николаевой М.А. и других ученых $[1 ; 2 ; 5 ; 8 ; 9]$. Авторы сходятся во мнении о наличии проблем на современном этапе подготовки будущих товароведения; предлагают свое видение путей их решения.

Как показало исследование Васильевой Н.О. с соавт. [2], в настоящее время высшее товароведное образование в Российской Федерации оказалось в сложной и неоднозначной ситуации. С одной стороны, переход страны к рыночной экономике создал реальные предпосылки роста востребованности профессиональных товароведных знаний, вызвал появление новых сфер их практического приложения. С другой стороны, на протяжении ряда лет наблюдается устойчивая тенденция снижения конкурса на направление подготовки «Товароведение», а также уровня знаний абитуриентов, его выбирающих.

Кроме того, нарушена содержательная преемственность между уровнями товароведного образования. Так, направление подготовки 38.03.07 входит в укрупненную группу «Экономика и управление», а программа подготовки научно-педагогических кадров в аспирантуре (специальность ВАК 05.18.15) - в технические науки. Причем, продолжение научной траектории развития знаний в аспирантуре по товароведению непродовольственных товаров, а также пищевых продуктов, не относящихся к продуктам функционального и специализированного назначения, с 2009 года не предусмотрено.

Ситуация еще более усугубляется тем, что в новой редакции Перечня специальностей и направлений подготовки ВО [11], предполагаемого к вступлению в действие с 1 сентября 2024 года и активно обсуждаемого в настоящее время образовательным сообществом, направление подготовки «Товароведение» интегрируется с направлением «Торговое дело» в единое направление 0606.0 - Торговая деятельность, частично сохраняя самостоятельность лишь в рамках направления 0506.0 - Экспертиза и товароведение изделий легкой промышленности. При этом в новой номенклатуре научных специальностей по-прежнему отсутствует специальность по товароведению и экспертизе непродовольственных и части продовольственных товаров.

В дополнение к перечисленному, утерян стимул к продолжению товароведного образования в вузе после получения специальности в системе среднего профессионального образования. Данное обстоятельство связано с необоснованным наименованием специальности СПО 38.02.05 - Товароведение и экспертиза качества потребительских товаров и присваиваемой после её освоения квалификации «товаровед-эксперт», явно несоответствующих объему и глубине содержания подготовки.

Согласно толковому словарю, эксперт - это лицо, обладающее специальными познаниями в конкретной области [10]. В связи с этим, по нашему убеждению, эксперт определенной товарной группы может сформироваться лишь после освоения соответствующей программы магистерской подготовки. В тоже время, необходимый багаж теоретических знаний в области товароведения и начальные навыки экспертной деятельности формируются у студентов на ступени бакалавриата, но не среднего профессионального образования. Существующее в настоящее время положение дел в системе СПО формирует искаженное представление о более широкой области профессиональной деятельности выпускника и достаточности знаний.

Аналогичная обеспокоенность по поводу будущего товароведного образования была высказана и на научно-методической конференции «Товароведение будущего», организованной в феврале 2021 года Российским экономическим университетом им. Г.В. Плеханова. Ведущие специалисты вузов России в качестве негативного момента указали на отсутствие в государственных и отраслевых планово-прогнозных документах концепции развития товароведного образования, определяющей цель и содержание подготовки бакалавров и магистров товароведения.

Выражая солидарность с мнением профессионального образовательного сообщества, выскажем собственное суждение о том, что причина стагнации современного товароведного образования в России может заключаться в неопределенности статуса самой науки «товароведение», неразрешенном до сих пор споре о принадлежности её к экономическим или естественнотехническим дисциплинам (Г.И. Андреев, А.В. Нестеров, Н.С. Перекалина, Ю.И. Сидоренко, С.В. Штерман). Как следствие, недостаточность фундаментальных исследований в этой области, о чем, по мнению М.А. Николаевой [7], свидетельствует отсутствие монографий и диссертаций по вопросам методологии товароведной науки.

Возможно, сложившаяся ситуация является следствием и того, что, окончательно выделившись из химии и технологии и сформировавшись в самостоятельную науку столетие назад, в настоящее время товароведение вступило в новый, интеграционный этап своего развития [7]. А, следовательно, потребуется некоторое время для теоретико-методологического осмысления проис- 
ходящих в данной науке изменений.

Однако, несмотря на определенные трудности в современном состоянии теоретического товароведения, потребность в практической подготовке товароведовэкспертов настоятельно диктует не только обновление содержания высшего товароведного образования, но и разработку новых, инновационных методов формирования готовности будущих бакалавров товароведения к профессиональной деятельности, в том числе экспертной.

Проблема готовности к какому-либо виду деятельности не нова для педагогической науки. Её теоретическое осмысление началось с 20-х годов прошлого века. В трудах П.П. Блонского, Н.К. Крупской, А.С. Макаренко готовность трактовалась как совокупность теоретических знаний, умений и навыков обучающегося. Концептуальные положения феномена готовности получили свое развитие в работах Б.Г. Ананьева, Ю.К. Бабанского, А.А. Бодалева, Е.А. Климова, Н.В. Кузминой, В.А. Крутецкого, А.К. Марковой, В.А. Сластенина, В.В. Серикова и других ученых.

В работах В.А. Адольфа, И.А. Колесниковой, Е.Ю. Степановой готовность к профессиональной деятельности рассматривается как необходимое условие формирования профессиональной компетентности. Аксиологические аспекты процесса формирования готовности к профессиональной деятельности исследованы в трудах И.А. Зимней, В.А. Сластенина, Г.И. Чижаковой.

Более того, в последнее десятилетие опубликовано достаточное количество исследований, в которых определены содержание, структура, условия готовности к профессиональной деятельности будущих педагогов (В.И. Байденко, И.А. Колесникова, Л.С. Селезнева, И.Ю. Степанова, Н.А. Токарева и другие), инженеров (О.С. Вялкова, И.С. Вологжанина, Н.И. Комарова и другие), экономистов (Т.Н. Ващило, М.М. Геращенко, Н.Н. Костина, И.Ю. Скибицкая, А.Г. Степанов и другие) и так далее.

В рамках научной специальности 13.00.08 «Теория и методика профессионального образования» диссертационными исследованиями в области товароведного образования занимались Николкина Н.Г. (2002 г.), Карташова Л.В. (2005 г.), Сорокина Н.Д. (2007 г.), Попова Е.М. (2009 г.), Гаврилова О.В. (2013 г.). В работах вышеперечисленных авторов изучены отдельные аспекты проблемы подготовки специалистов-товароведов в системе среднего профессионального и высшего образования.

Высоко оценивая результаты научного поиска ученых-педагогов и признавая значимость указанных работ для нашего исследования, должны отметить, что публикаций, посвященных формированию готовности бакалавров - будущих товароведов-экспертов к профессиональной деятельности в открытой печати не обнаружено. В связи с этим целью настоящей статьи является научное обоснование и описание авторского метода формирования рассматриваемого вида готовности.

\section{Материалы и методы}

Методологическую основу исследования составили системный, деятельностный и рефлексивный подходы. Обоснуем правомерность применения каждого из них.

В области методологии системного анализа для нашего исследования особую роль сыграли труды российских ученых А.Н. Аверьянова, И.В. Блауберга, С.М. Бреховских, Ю.А. Воронина, М.С. Кагана, В.Н. Сагатовского, А.И. Уемова, Б.Г. Юдина. Среди работ зарубежных авторов отдельно укажем публикации М. Месаровича [Mesarovich], Я. Такахара [Takahara], П. Колет [Kolet], А. Холла [Holl] [4].

Системный подход является междисциплинарным и широко используется при изучении педагогических систем [3]. Его уникальность состоит в рассмотрении объекта исследования как системы, характеризующейся тремя группами факторов, а именно:

1) системопорождающих;

2) системообразующих;

3) системообусловливающих [12].

Системопорождающая группа детерминант, в свою очередь, включает следующие компоненты:

1.1) целевое состояние;

1.2) противоречие.

Очевидно, что целью настоящего исследования явилось определение педагогических условий формирования готовности бакалавра товароведения к профессиональной экспертной деятельности. Основным противоречием при этом авторы исследования считают противоречие между нарастающей потребностью государства и общества в профессиональных экспертных кадрах и недостаточным вниманием системы высшего товароведного образования к удовлетворению указанной потребности.

Системообразующие факторы в рамках настоящего исследования определяются содержанием и структурой профессиональной подготовки будущих товароведовэкспертов.

Наконец, третья группа детерминант - системообусловливающие факторы. Они задаются, прежде всего, условиями внешней среды. Эта среда накладывает совокупность ограничений на сохранение, функционирование и развитие объекта как системы, тем самым обе- 
спечивая в заданных пределах её воспроизводство [4]. В рамках настоящего исследования внешней средой выступает профессиональное сообщество, определяющее принципы, нормы, этические требования к профессиональной деятельности эксперта.

Деятельностный подход определяет сущность и характер действий будущих бакалавров товароведения по формированию практических навыков экспертной деятельности. При этом особое внимание, по нашему мнению, должно быть направлено на формирование ряда компетенций, как общепрофессиональных, определенных ФГОС ВО [13], так и профессиональных, сформированных вузом самостоятельно или в соавторстве с профессиональным экспертным сообществом. Перечень этих компетенций может иметь, например, следующий вид:

- способность использовать современные методы исследования, оценки и экспертизы товаров (ОПК-2);

- способность применять действующие нормативные правовые акты и нормативные документы в сфере обеспечения качества, безопасности и предупреждения оборота фальсифицированной продукции (ОПК-З);

- способность применять методы идентификации, оценки качества и безопасности товаров для диагностики дефектов, выявления опасной, некачественной, фальсифицированной продукции (ПК);

- способность готовить заключения о соответствии качества сырья или товара нормативным требованиям (ПК).

Рефлексивный подход инициирует осмысление и оценку обучающимся осуществления и результатов своей экспертной деятельности.

\section{Результаты}

Основываясь на описанной выше методологической базе и обобщая собственный многолетний опыт профессиональной подготовки товароведов-экспертов, а также опыт плодотворного сотрудничества в образовательной сфере с ФБУ «Государственный региональный центр стандартизации, метрологии и испытаний в Красноярском крае, Республике Хакасия и Республике Тыва» (далее ФБУ «Красноярский ЦСМ»), нами была сформирована программа профессиональной подготовки «Путь в специальность». Ядром предлагаемой авторской программы формирования готовности бакалавра товароведения к профессиональной экспертной деятельности является вовлечение обучающихся в процесс подготовки и реализации процедуры потребительского тестирования товаров с последующим анализом полученных данных и рефлексией собственных достижений. Программа предполагает последовательную реализацию нескольких этапов:

1. Выбор объекта исследования. На основании заявок, размещаемых активными потребителями на сайте «Проднадзор.инфо», разработанном и поддерживаемым ФБУ «Красноярский ЦСМ», или на странице кафедры товароведения и экспертизы товаров в социальных сетях (раздел «СФУ за качество жизни»), а также по результатам потребительского голосования ежемесячно осуществляется выбор товара, подлежащего экспертизе.

2. Формирование экспертной группы. В зависимости от принадлежности объекта исследования к товарной группе определяется студенческий курс, который уже изучил или находится в стадии изучения данной товарной группы. Численность учебной группы, как правило, составляет 15-18 человек, поэтому все студенты участвуют в реализации проекта.

3. Подготовка экспертной группы к участию в проекте. На подготовительном этапе, продолжительность которого не превышает одну учебную неделю, студентам дается задание подобрать и изучить действующие нормативно-правовые и нормативно-технические документы на объект исследования. Выявить показатели безопасности и качества, а также методики их определения. На основе нормативно-технической документации разработать балльную систему оценки показателей качества исследуемого товара. Кроме того, студенты должны изучить правила транспортировки и хранения образцов исследуемой группы товаров.

4. Приобретение объектов исследования. Экспертная группа под руководством специалиста ФБУ «Красноярский ЦСМ» в розничной торговой сети приобретает образцы для исследования. При этом, если продукция производится и в Красноярском крае, то образцы выбираются как местных товаропроизводителей, так и из других регионов РФ, а также импортные товары. Затем объекты исследования делятся на две одинаковые по составу партии, одна из которых с соблюдением требований, предъявляемых к транспортировке и хранению, доставляется в испытательный центр ФБУ «Красноярский ЦСМ», а вторая - в испытательную лабораторию университета.

5. Описание объектов исследования. После поступления образцов в университетскую лабораторию члены экспертной группы внимательно изучают и описывают состояние потребительской упаковки исследуемых товаров, акцентируя внимание на её целостности, надежности крепления товара внутри упаковки, соответствия используемых материалов упаковки предъявляемым требованиям. Также внимательно исследуются маркировочные реквизиты. По итогам исследования делается соответствующее заключение по каждому образцу. 
Затем преподаватель, курирующий работу данной экспертной группы, составляет акт шифровки образцов с последующим их обезличиванием с целью получения максимально объективной информации на этапах инструментального и органолептического исследования.

6. Инструментальные испытания объектов исследования. Данный этап параллельно реализуется в условиях испытательного центра ФБУ «Красноярский ЦСМ» в области его аккредитации, а также в университетской лаборатории членами студенческой экспертной группы в рамках технических возможностей вуза. Полученные результаты сопоставляются, анализируются и сравниваются со стандартными значениями, определяемыми ГОСТами или техническими условиями, или заявленными производителем.

7. Испытание объектов исследования методами сенсорного анализа. Для реализации данного этапа формируется расширенная экспертная группа, в состав которой, помимо студентов, входят преподаватели кафедры, специалисты ЦСМ, представители организаций-производителей, независимые эксперты, специализирующиеся на данной товарной группе. Путем открытого голосования выбирается руководитель расширенной экспертной группы. В специально оборудованном помещении эксперты оценивают обезличенные объекты исследования по внешнему виду, запаху, цвету, прозрачности, вкусу и т.д. Затем результаты экспертной оценки образцов обрабатываются и оглашаются председателем комиссии.

8. Анализ полученных результатов экспертизы. После завершения этапов инструментального и сенсорного анализа полученные результаты обрабатываются студентами - членами экспертной группы и в соответствии с актом шифровки образцов на каждый исследуемый товар составляется экспертное заключение. В констатирующей части данного документа указываются выявленные отклонения товара от нормативных требований, а в постановляющей части - формулируется решение эксперта о возможности реализации товара в розничной торговой сети.

9. Этап рефлексии, в ходе которого происходит осмысление и оценка обучающимся осуществления и результатов своей экспертной деятельности. В ходе этого этапа студент заполняет анкету, ответы на вопросы которой и запускают механизмы рефлексивной деятельности.

\section{Обсужмение}

Справедливости ради необходимо отметить, что практика проведения потребительского тестирования товаров различного назначения возникла не сейчас. Еще в советское время проводилась опытная носка новых образцов одежно-обувных изделий, экспериментальная эксплуатация новых видов сложной бытовой техники, дегустация произведенных по измененной рецептуре или инновационной технологии пищевых продуктов. В первое десятилетие XXI века потребительский рынок России оказался насыщен пищевыми и непродовольственными товарами импортного производства, причем различного качества. В это же время государство оставило за собой лишь гарантию безопасности товаров, перейдя от ГОСТов к Техническим регламентам Таможенного Союза, а производители, воспользовавшись введением в действие Федерального закона № 184-Ф3, активно стали переходить при производстве продукции с государственных стандартов на технические условия (ТУ). Начала расцветать недобросовестная конкуренция, так как в условиях отсутствия твердых ориентиров качества качественные товары стали проигрывать фальсифицированным по цене и, соответственно, спросу [6].

Именно в это время возрождается интерес к потребительскому тестированию. На центральных и местных каналах телевидения особую популярность приобретают программы «Контрольная закупка», «Наш потребнадзор» и подобные. В сети Интернет повышенный интерес пользователей стали вызывать сайты, на которых надзорные органы и экспертные организации представляют результаты мониторинга качества различных видов потребительских товаров: РосТест, Росконтроль.ру, Проднадзор.инфо и другие.

Запрос общества на достоверную информацию о качестве продукции различных производителей, реализуемую в розничной торговле, с одной стороны, и необходимость подготовки специалистов в области экспертизы безопасности и качества потребительских товаров, с другой стороны, послужили толчком для проведения кафедрой товароведения и экспертизы товаров Сибирского федерального университета и ФБУ «Красноярский ЦСМ» в 2015 году эксперимента по потребительскому тестированию студентами - будущими товароведамиэкспертами - сливочного масла, произведенного как в Красноярском крае, так и за его пределами.

Результаты эксперимента оказались ошеломляющими.

Во-первых, данное событие вызвало большой интерес у региональных СМИ, и на следующий день студенты, участвовавшие в тестировании, в прямом смысле проснулись знаменитыми: с экранов телевизоров их увидели родные и знакомые, их стали узнавать в лицо в университете, с ними стали советоваться по вопросу выбора и других товаров. Это обстоятельство повысило собственную самооценку, а, главное, понимание важности и нужности выбранной специальности. 
Во-вторых, участники эксперимента прочувствовали меру ответственности при формировании экспертного заключения. За каждым тестируемым образцом стоял коллектив предприятия-производителя, и любая допущенная оплошность при предъявлении мнения эксперта могла стать причиной серьезных репутационных потерь организации. Как следствие, сформировалось понимание необходимости обосновывать и подтверждать каждый вывод эксперта результатами объективных анализов и испытаний.

B-третьих, при подготовке процедуры тестирования, формировании дегустационных листов вскрылось несовершенство, наличие большого количества пробелов в нормативно-правовой и нормативно-технической документации. Данное обстоятельство заставило не только тщательно работать с имеющимися на данный вид продукции документами, но и творчески перерабатывать нормативные акты, относящиеся к близким товарным группам.

В-четвертых, участники эксперимента получили возможность увидеть изнутри работу профессиональных экспертов - ведущих специалистов ФБУ «Красноярский ЦСМ», поработать с ними в одной команде. Глубина знаний высококвалифицированных специалистов, владение широким спектром методов экспертной деятельности, умение ясно и четко формулировать выводы - все это произвело на студентов неизгладимое впечатление.

Наконец, в-пятых, студенты, участвовавшие в потребительском тестировании, пересмотрели свое отношение к целому ряду учебных дисциплин, ранее воспринимаемых как неважные, малозначимые с точки зрения получения специальности.

Практика реализации рассматриваемой инноваци- онной формы вовлечения студентов - будущих бакалавров товароведения в профессиональную деятельность на протяжении последующих шести лет подтвердила её эффективность и результативность. Об этом свидетельствуют результаты опроса участников проекта, 93-95 \% которых (в разные годы) считают, что участие в данной программе способствовало формированию их готовности к дальнейшей профессиональной деятельности. 87-89 \% опрошенных получили целостное, системное представление об экспертной деятельности. 62,5-67 \% участников программы в разные годы отмечали, что открыли для себя новые инструменты и процедуры в деятельности эксперта потребительских товаров. Более 50 \% респондентов определились с будущим местом работы в ходе участия в рассматриваемой программе.

\section{Зак^ючение}

Таким образом, резюмируя вышеизложенное, отметим, что проблема формирования готовности выпускника вуза к профессиональной деятельности остается актуальной, что свидетельствует о высоком уровне сложности и недостаточной эффективности используемого теоретико-методического инструментария для её решения. Одним из возможных вариантов её разрешения в области товароведного образования может стать реализация программы «Путь в специальность», методологическим базисом которой выступила совокупность системного, деятельностного и рефлексивного подходов. Ядром данной программы явилось вовлечение будущих бакалавров товароведения в процесс подготовки и реализации процедуры потребительского тестирования товаров с последующим анализом полученных данных и рефлексией собственных достижений. Опыт внедрения указанной программы в образовательную практику Сибирского федерального университета подтвердил её эффективность и результативность.

\section{ЛИТЕРАТУРА}

1. Бакайтис В.И. Товароведение как направление подготовки специалистов в историческом аспекте / В.И. Бакайтис, Ю.Ю. Миллер, Е.Б. Табала // Технологии в образовании - 2021: Сборник материалов Международной научно-методической конференции, Новосибирск, 21-25 апреля 2021 года / Под общей редакцией Е.В. Добровольской. - Новосибирск: Сибирский университет потребительской кооперации, 2021. - С. 176-181.

2. Васильева Н.О. Проблемы и перспективы образовательной области «Товароведение» / И.В. Кротова, Н.О. Васильева // Наука в XXI веке: проблемы, поиски, решения: материалы НПК с междун. участием, посвященной 75-летию Победы в Великой Отечественной Войне, Миасс, 21 февраля 2020 г. - Курган: Изд-во Курганского гос. ун-та - С. 110-119.

3. амалеева А.Р. Системный подход в педагогике /А.Р. Камалеева// Научно-педагогическое обозрение. Pedagogical Review. - 2015. - т. 3 (9). - c. 13-23.

4. К Кротова И.В. Оптимизация совместимости учебной наглядности (на примере учебников средней школы): дисс. . .д-ра пед. наук. - Курган, 2009. - 388 с.

5. Кротова И.В. Методические подходы к разработке профессионального стандарта "Товаровед непродовольственных товаров" / И.В. Кротова, Е.А. Сапсаева, Э.В. Савицкая // Полихотомические классификации специальных терминов в научной и учебной литературе: Материалы межрегионального тематического сборника с международным участием / Министерство науки и высшего образования Российской Федерации; Федеральное государственное бюджетное образовательное учреждение высшего образования «Челябинский государственный университет»; Миасский филиал Международная академия фундаментального образования. - Курган: Курганский государственный университет, 2021. - С. 290-300.

6. Моргун В.Н. Мониторинг качества товаров как эффективный метод контроля потребительской продукции / В.Н. Моргун, Т.В. Мельник // Контроль 
качества продукции. - 2018. - № 11. - С. 47-52.

7. Николаева М.А. Актуальные проблемы научного товароведения / М.А. Николаева // Индустрия питания|Food Industry. - 2017. - № 3. - C. $46-51$.

8. Николаева М.А. Актуальные проблемы подготовки и востребованности товароведов на рынке труда / М.А. Николаева, О.В. Евдокимова, Т.Н. Иванова // Индустрия питания |Food Industry. - 2020. - Т. 5, № 1. - С. 71-80.

9. Николаева М.А. Товаровед - необходимая в торговле специальность / М.А. Николаева, Л.Г. Елисеева, Т.Н. Иванова // Товаровед продовольственных товаров. - 2019. - № 2. - С. 46-49.

10. Ожегов С.И., Шведова Н.Ю. Толковый словарь русского языка. - 3 изд., стер. - Москва: Азъ, 1996. - 907 с.

11. Проект Приказа Министерства науки и высшего образования РФ "0б утверждении перечней специальностей и направлений подготовки высшего образования" (подготовлен Минобрнауки России 12.05.2021). - Режим доступа: https://minobrnauki.gov.ru/press-center/news/?ELEMENT_ID=33550

12. Сагатовский В.Н. Системная деятельность и ее философское осмысление: материалистическая диалектика и системный подход / В.Н. Сагатовский. Л.: ЛГУ, 1982. -274 С.

13. Федеральный государственный образовательный стандарт высшего образования - бакалавриат по направлению подготовки 38.03 .07 Товароведение (утв. приказом Минобрнауки России 12 августа 2020 г. № 985). - Режим доступа: http://fgosvo.ru/news/21/4846

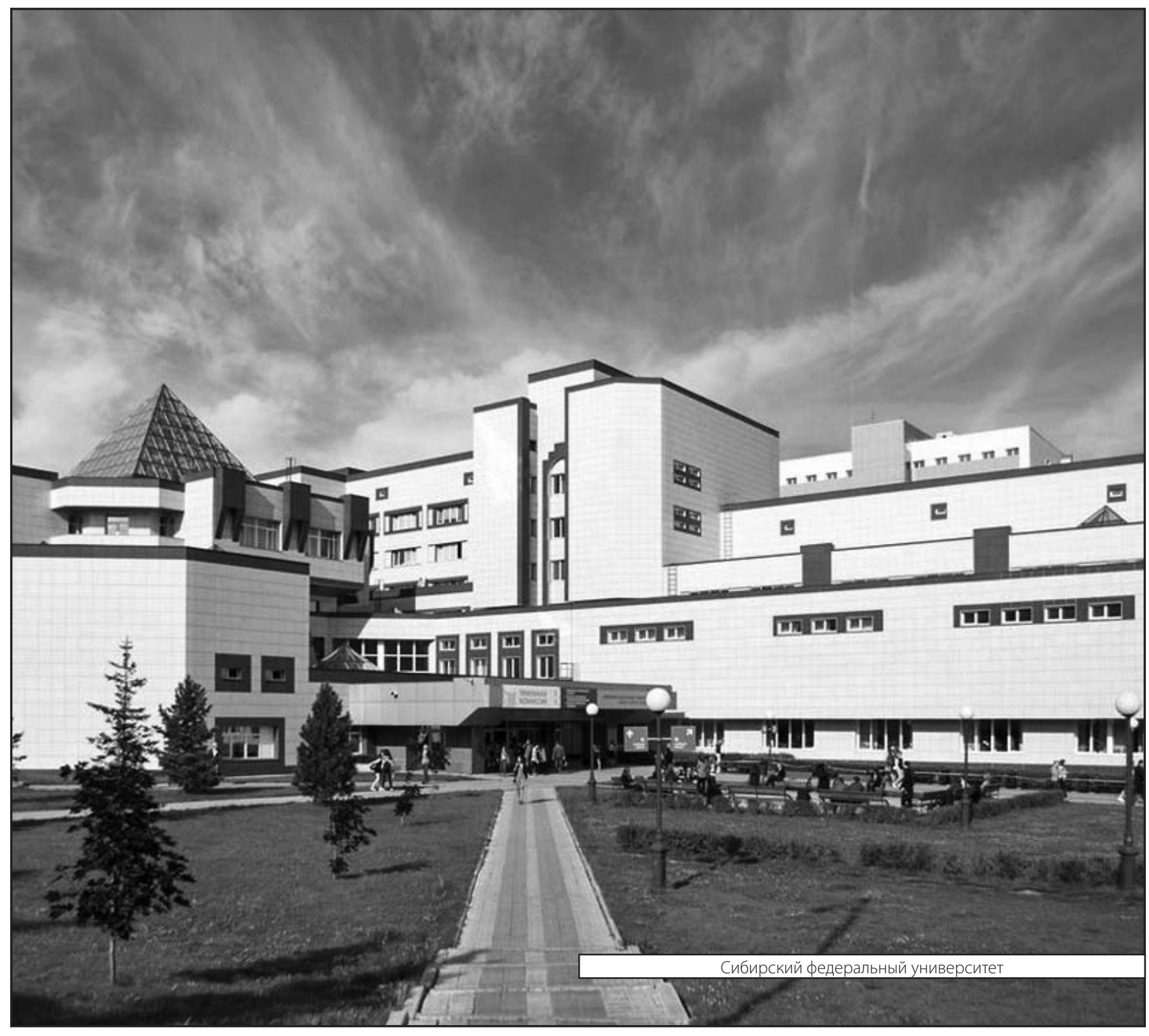

